\section{RMD Open}

Rheumatic \&

Musculoskeletal Diseases

\title{
Juvenile idiopathic arthritis and risk of cancer before and after the introduction of biological therapies
}

AnnaCarin Horne (D , ${ }^{1}$ Bénédicte Delcoigne, ${ }^{2}$ Karin Palmblad, ${ }^{3}$ Johan Askling ${ }^{2}$

To cite: Horne A, Delcoigne $B$, Palmblad K, et al. Juvenile idiopathic arthritis and risk of cancer before and after the introduction of biological therapies. RMD Open 2019:5:e001055. doi:10.1136/ rmdopen-2019-001055

- Additional material is published online only. To view please visit the journal online (http://dx.doi.org/10.1136/ rmdopen-2019-001055).

Received 15 July 2019 Revised 21 October 2019 Accepted 22 October 2019
Check for updates

(C) Author(s) (or their employer(s)) 2019. Re-use permitted under CC BY-NC. No commercial re-use. See rights and permissions. Published by BMJ.

${ }^{1}$ Department of Women's and Children's Health, Karolinska Institute, Stockholm, Sweden ${ }^{2}$ Clinical Epidemiology Division, Department of Medicine Solna, Karolinska Institute, Stockholm, Sweden

${ }^{3}$ Pediatric Rheumatology, Karolinska Hospital, Stockholm, Sweden

Correspondence to Dr AnnaCarin Horne; annacarin.horne@sll.se

\section{ABSTRACT}

Background The risk of cancer, including any secular trends in risk, in patients with juvenile idiopathic arthritis (JIA) is incompletely understood.

Methods We performed a register-based cohort study of patients with JIA from 2001 until 2017, identified via the Swedish Patient Register. Patients with JIA were matched to five population reference subjects. Patients and referents were followed up for incident cancers (via linkage to the Swedish Cancer Register) until 18 years of age or 31 December 2016.

Results Among the 6721 patients with JIA, we observed 10 incident malignancies (5 lymphoproliferative cancers) during 34951 person-years of follow-up, corresponding to an excess incidence of 0.09 cancers per 1000 personyears (one extra case per 11000 patients per year), an HR for cancer (all sites) of 1.4 (95\% Cl 0.7 to 2.9$)$ and an HR for lymphoproliferative malignancies of $3.6(95 \% \mathrm{Cl} 1.1$ to 11.2). The rates of cancer in JIA did not increase over the study period. We noted no differences in the excess risk comparing periods before and after the introduction of biologic disease-modifying antirheumatic drugs (bDMARDs).

Discussion Children and adolescents with JIA are at a slightly increased risk of lymphoproliferative (but not of other) malignancies. At the group level, there is no sign that this risk has increased further after the introduction of bDMARDs.

\section{INTRODUCTION}

Without treatment, juvenile idiopathic arthritis (JIA) may have devastating consequences. ${ }^{1-4}$ The long-term impact of active disease in JIA on cancer risks is only partly understood. The few available studies suggest that patients with JIA may be at increased risk for lymphoproliferative malignancies in childhood and early adulthood. ${ }^{5}{ }^{6}$ In a previous study, covering an essentially biologics-naive JIA cohort followed for cancer up until 2007, we reported a twofold to fourfold increased risk of lymphoproliferative malignancies. ${ }^{7}$

Biologic disease-modifying antirheumatic drugs (bDMARDs) such as tumour necrosis factor inhibitors have revolutionised the

\section{Key messages}

What is already known about this subject?

- Earlier studies suggest that patients with juvenile idiopathic arthritis (JIA) may be at increased risk for lymphoproliferative malignancies in childhood and early adulthood (not clear however if this is due to the rheumatic disease itself or its treatment).

What does this study add?

- We confirmed earlier results by demonstrating an increased but low risk mainly for lymphoproliferative cancers.

- Despite the increased usage of biological therapies over the past 20 years, there is no sign that the risk of cancer in patients with JIA has increased over this period.

How might this impact on clinical practice?

- This study increased reassurance regarding nonincreased cancer risk when considering whether to use biological therapies.

- Malignancies in patients with JIA should be monitored continuously to provide longer-term risk assessment.

treatment of JIA. $^{1}$ Ever since the initial approval of bDMARDs, there have been concerns about a potential increased risk of malignancy. ${ }^{8}$ The interpretation of available studies on this topic (outlined in online supplementary table 2$)^{579-13}$ is limited by the relatively small number of patients with JIA, the low incidence of paediatric malignancy and the possibility that the treated disease itself increases the risk. Although the safety profile of bDMARDs is generally well understood, some worries remain. ${ }^{8-12}$ For instance, fear of long-term cancer risk is one reason that patients (or their parents and prescribers) are reluctant to try what may otherwise be both a needed and effective therapy.

The aim of this study was therefore to assess the risk of cancer in children with JIA, in particular to assess contemporary risks and 
how these may have changed compared with the prebiological era.

\section{PATIENTS AND METHODS}

We performed a register-based cohort study using data from prospectively recorded Swedish nationwide and virtually complete registers from the Swedish tax-funded healthcare system. The approach and registers used are described in more detail in online supplementary text 1 .

\section{Study cohorts}

From the Swedish Patient Register, we identified a JIA cohort of 6721 individuals with at least two inpatient or outpatient visits registered with JIA (M05-M09 on the International Classification of Diseases (ICD)-10) before the age of 17 years from 2001 through 2016, but without any hospitalisation with a JIA diagnosis before 2001. The two visits had to be registered within 2 years from each other. Using the Swedish Population Register, we identified a general population comparator cohort of 33774 individuals individually matched (1:5) to the JIA cohort on age and sex. Each referent had to be alive at the date of the second JIA diagnosis of its index individual with JIA.

\section{Follow-up and outcome}

Through linkage of the JIA and population cohorts to the Swedish Cancer Register, we identified all incident cancers (excluding basal cell carcinomas). Hodgkin's and non-Hodgkin's lymphoma (ICD-10: C8), acute and chronic lymphocytic leukaemia (C91), and multiple myeloma (C90) were categorised as lymphoproliferative malignancies and analysed as a separate outcome.

Follow-up began 6 months after the index date and ended at emigration, death, first ever cancer, 18 years of age (the ageof transition from pediatric to adult care) and 31 December 2016, whichever came first. General population individuals were additionally censored at the date of first JIA diagnosis (if any). Individuals with a history of cancer by the start of follow-up were excluded.

\section{Statistical analyses}

We calculated incidences of malignancies and compared these using HR from Cox models adjusted for sex and age and using time since start of follow-up as time scale. Further adjustment included the year of first visit listing JIA.

\section{Sensitivity analyses}

We performed several sensitivity analyses. First, we reran the main analysis, but extended follow-up through a maximum of 33 years of age at end of follow-up (31 December 2016). Second, we used additional time scales; we hypothesised that as bDMARD use has increased, any (harmful) effect of bDMARDs on cancer risk would be reflected in an increased incidence of cancers with calendar time. While we had adjusted for calendar year in our main analysis, we also used calendar time as time
Table 1 Characteristics of patients with JIA and general population individuals, and of cancer cases (all sites) in patients with JIA and general population individuals

\begin{tabular}{|c|c|c|}
\hline Variables & $\begin{array}{l}\text { Patients with } \\
\text { JIA }\end{array}$ & $\begin{array}{l}\text { General } \\
\text { population } \\
\text { (matched) }\end{array}$ \\
\hline \multicolumn{3}{|l|}{ All individuals } \\
\hline $\begin{array}{l}\text { Number of subjects } \\
\text { (\% girls) }\end{array}$ & $6721(64)$ & 33774 (64) \\
\hline \multicolumn{3}{|l|}{$\begin{array}{l}\text { Start of follow-up } \\
\text { (number of subjects, } \\
\% \text { of total) }\end{array}$} \\
\hline 2001-2003 & $1335(20)$ & $6695(20)$ \\
\hline 2004-2007 & 1971 (29) & 9958 (29) \\
\hline 2008-2011 & $1646(24)$ & $8259(24)$ \\
\hline 2012-2016 & $1769(26)$ & $8862(26)$ \\
\hline $\begin{array}{l}\text { Median age (years) } \\
\text { at start of follow-up } \\
\text { (p25-p75) }\end{array}$ & $10(5-13)$ & $10(5-13)$ \\
\hline \multicolumn{3}{|l|}{ Cases with cancer } \\
\hline $\begin{array}{l}\text { Number of cancer } \\
\text { cases } \\
\text { (\% with } \\
\text { lymphoproliferative } \\
\text { malignancies) }\end{array}$ & $10(50)$ & $35(20)$ \\
\hline $\begin{array}{l}\text { Median age (in years) } \\
\text { at cancer diagnosis } \\
\text { (p25-p75) }\end{array}$ & $11.7(9.4-14.0)$ & $13.6(9.4-15.8)$ \\
\hline $\begin{array}{l}\text { Median follow-up time } \\
\text { (in years) until cancer } \\
\text { diagnosis } \\
\text { (p25-p75) }\end{array}$ & $2.1(0.4-3.3)$ & $3.9(1.1-5.9)$ \\
\hline
\end{tabular}

JIA, juvenile idiopathic arthritis; p25, percentile 25; p75, percentile 75.

scale and split the scale into intervals to visualise how the cancer rates varied across calendar time periods. In addition, we used attained age as time scale and split the time into 5-year categories. Further, we used Poisson regressions to specifically investigate, within the JIA cohort, the role of time of follow-up, calendar time and attained age on cancer risks. Finally, we reran all analyses including only (incident) JIA first identified in 2003 or later, that is, after washout of any prevalent JIA included in 2001 and 2002 (online supplementary figure 1).

\section{RESULTS}

Table 1 presents the characteristics of the study population. Among the 6721 patients with JIA, 10 incident malignancies (among which 5 were lymphoproliferative cancers) were observed during 34951 person-years of follow-up (incidence $=0.29$ per 1000 person-years) from 2001 through 2016. In the matched population cohort, 35 incident malignancies (7 lymphoproliferative) were identified during 174529 person-years of follow-up 
Table 2 Number of patients with JIA and general population individuals, number of incident cancer cases, person-years, standardised incidence rates and Cox HR with 95\% Cl.

\begin{tabular}{|c|c|c|c|c|c|c|}
\hline & Individuals (n) & Cancers (n) & Person-years & $\begin{array}{l}\text { Incidence } \\
\text { (/1000 } \\
\text { person- } \\
\text { years) }\end{array}$ & HR & $95 \% \mathrm{Cl}$ \\
\hline \multicolumn{7}{|l|}{ A. Follow-up until age 18} \\
\hline \multicolumn{7}{|l|}{ All cancer } \\
\hline JIA & 6721 & 10 & 34951 & 0.29 & 1.43 & 0.71 to 2.88 \\
\hline General population & 33774 & 35 & 174529 & 0.20 & & \\
\hline \multicolumn{7}{|c|}{ Lymphoproliferative malignancies } \\
\hline JIA & 6721 & 5 & 34951 & 0.14 & 3.57 & 1.13 to 11.24 \\
\hline General population & 33774 & 7 & 174529 & 0.04 & & \\
\hline \multicolumn{7}{|c|}{ B. Follow-up through all ages } \\
\hline \multicolumn{7}{|l|}{ All cancer } \\
\hline JIA & 6721 & 18 & 55107 & 0.33 & 1.10 & 0.66 to 1.84 \\
\hline General population & 33814 & 82 & 276383 & 0.30 & & \\
\hline \multicolumn{7}{|c|}{ Lymphoproliferative malignancies } \\
\hline JIA & 6721 & 7 & 55107 & 0.13 & 3.19 & 1.24 to 8.24 \\
\hline General population & 33814 & 11 & 276383 & 0.04 & & \\
\hline
\end{tabular}

JIA, juvenile idiopathic arthritis.

(incidence $=0.20$ ), which gives an excess incidence of 0.09 cancers per 1000 person-years in the JIA population (one extra case per 11000 patients per year), an HR for all-site cancer of 1.4 (95\% CI 0.7 to 2.9), an HR for lymphoproliferative malignancies of 3.6 (95\% CI 1.1 to 11.2 ), and an HR for all sites but lymphoproliferative cancers of 0.89 (95\% CI 0.34 to 2.31) (table 2, Part A and figure 1A,D). Online supplementary table 3 shows drug information available for each of the patients with JIA diagnosed with cancer, detailing the specific type of cancer and lymphoproliferative disorder.

\section{Sensitivity analyses}

Extending the follow-up through all available ages increased the person-time of follow-up to 55107 personyears and the number of incident cancers to 18 in the JIA cohort, but had only minor impact on the relative risk estimates for all cancers $(\mathrm{HR}=1.1)$ and for lymphoproliferative cancers $(\mathrm{HR}=3.2)$ (table 2, Part $\mathrm{B}$ ). None of the adjustments substantially altered these HRs (data not shown).

Using calendar time as time scale and comparing the different calendar periods suggested that the rates of cancer (all types and lymphoproliferative specifically) in JIA did not increase over calendar time $(p>0.2)$ (figure 1B). When we used attained age as time scale, we found that the risk of developing cancer in the JIA cohort (but not in the general population) was relatively constant across age (figure $1 \mathrm{C})(\mathrm{p}=0.56)$. The Poisson regression analyses did not reveal any additional feature not captured by the Cox models. When we reran the analyses on the JIA cohort applying a washout of prevalent patients, the results were similar (online supplementary table 1 and online supplementary figure 2).

For patients with JIA still in the cohort in 2006 (ie, first year for the Prescribed Drug Register) and followed up until 18 years of age, $2037(32 \%)$ had a subcutaneous bDMARD treatment recorded at least once during follow-up. For patients with JIA still in the cohort in 2015, this percentage was $54 \%$, indicating the sharp increase in biologics use with calendar time. Among the six patients with JIA diagnosed with cancer in 2006 or later, only one had a bDMARD treatment recorded during follow-up. We also observed that all patients with JIA diagnosed with cancer continued to have visit codes with JIA after their cancer diagnosis. Finally, when we compared our findings with our previous estimates, we noted a consistency across analyses and no calendar period difference (online supplementary figure 3).

\section{DISCUSSION}

In this study of almost 7000 Swedish patients with JIA, we confirm that the risk for patients with JIA to develop cancer is low, with one extra case of cancer per every 11000 patients per year. Our current study confirms and extends the findings from Simard $e t a l^{7}$ that the risk of developing lymphoproliferative malignancy in children with JIA was statistically significantly higher than in non-JIA children. Since that report, the penetration of bDMARD use has increased dramatically. Indeed, in 2016, around $40 \%$ of patients in Sweden with JIA had been treated or were on treatment with biological therapy (data from the annual report of the Swedish national 
A
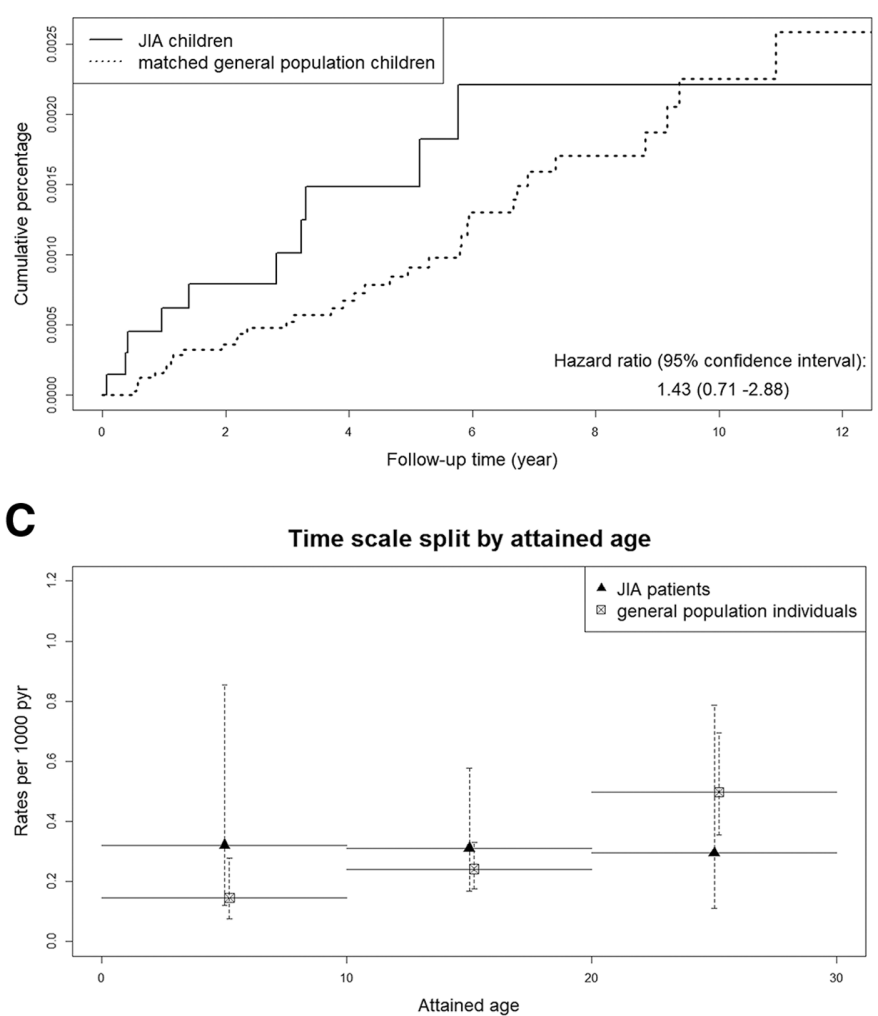

B

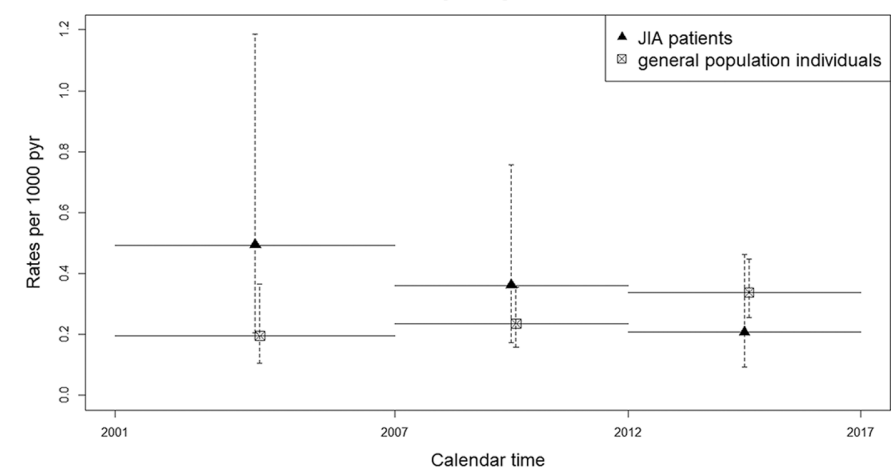

D

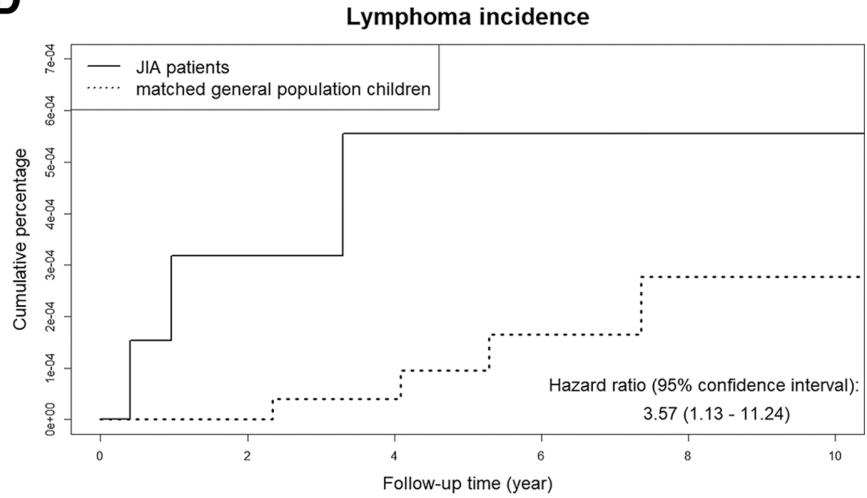

Figure 1 Cumulative incidence of cancer overall (A) and of lymphoproliferative malignancies (D) in patients with JIA and general population matched children. Incidence of cancer by calendar time (B) and attained age (C) in patients with JIA and general population matched children. The study period is 2001-2016 and follow-up stops at an attained age of 18 years. JIA, juvenile idiopathic arthritis; pyr, person-years.

paediatric rheumatology quality registry, http://barnreumaregistret.se/wp-content/uploads/2017/10/Barnreumaregistret-Årsrapport-2016.pdf). Importantly, despite a sharp increase in the use of bDMARDs, we observed no calendar trends in the excess risk of cancer.

Our study has a few limitations. First, despite being large in comparison with previous studies, statistical precision was still limited, which, along with insufficient phenotypic detail for many patients, precluded stratification by specific JIA subtype. Although we could identify bDMARD treatment, this information was only available from July 2005 through 2016. As we had very few cancer outcomes in our JIA cohort, we were unable to make formal assessments of risks per individual drug.

Our study has several strengths. The use of populationbased registers of high coverage meant that we could include the vast majority of all JIA in the general population, identify a population-based general population comparator cohort matched to the JIA cohort, and identify incident cancers of high diagnostic accuracy and independently of exposure status.

To further reduce the risk that the symptoms were in reality a malignancy, rather than JIA, we excluded the first 6 months of follow-up after initial JIA presentation and noted that all incident cancer cases in the JIA cohort continued to have visits listing JIA even after their cancer diagnosis. This argues against misclassification of the cancer as JIA (or vice versa).

In summary, our study showed that patients with JIA are at increased risk of developing malignant lymphoma compared with the general population, but the absolute risk is very low. There is no sign that the risk of cancer in patients with JIA has been increasing over the past 20 years, during which time treatment with bDMARDs has become common. This apparent absence of risk should be reassuring for both prescribers and patients/their parents.

Acknowledgements The authors would like to acknowledge Madeleine Beerman, Chair of the Rheumatic Youth Organization of Sweden, 2015-2019.

Contributors $\mathrm{ACH}, \mathrm{BD}$ and $\mathrm{JA}$ made the study design. BD gathered and analysed the data. ACH drafted the manuscript, and all authors revised the paper in keeping with important content and provided final approval before publishing. All authors agreed to be accountable for the accuracy of the work.

Funding This study was supported by the Swedish Rheumatism Association.

Competing interests $\mathrm{ACH}$ has received speakers compensation from Sobi and Novartis. JA has or has had research agreements with AbbVie, BMS, MSD, Pfizer, Roche, AstraZeneca, Eli Lilly, Samsung Bioepis and UCB, mainly in the context of safety monitoring of biologics via ARTIS. Speakers bureau: Karolinska Hospital has received compensation for $\mathrm{ACH}$ from AbbVie and SOBI. The Karolinska Institute has received remuneration for JA participating in advisory boards arranged by Pfizer and Eli Lilly.

Patient and public involvement statement We have patient representatives, both in the clinic and in research. The chair of the Rheumatic Youth Organization of Sweden is our main representative and support our current study and agree that 
it is of greatest importance. The Rheumatic Youth Organisation and the Swedish Rheumatism Association will help distribute our results so they reach all affected patients and families physicians as well as physicians

Patient consent for publication Not required.

Ethics approval The Regional Ethical Review Board in Stockholm granted ethical approval (DNR: 2015/1844-31/2).

Provenance and peer review Not commissioned; externally peer reviewed.

Data availability statement Data are available upon reasonable request.

Open access This is an open access article distributed in accordance with the Creative Commons Attribution Non Commercial (CC BY-NC 4.0) license, which permits others to distribute, remix, adapt, build upon this work non-commercially, and license their derivative works on different terms, provided the original work is properly cited, appropriate credit is given, any changes made indicated, and the use is non-commercial. See: http://creativecommons.org/licenses/by-nc/4.0/.

ORCID iD

AnnaCarin Horne http://orcid.org/0000-0002-2878-4463

\section{REFERENCES}

1 Stoll ML, Cron RQ. Treatment of juvenile idiopathic arthritis: a revolution in care. Pediatr Rheumatol Online J 2014;12.

2 Shoop-Worrall SJW, Verstappen SMM, Baildam E, et al. How common is clinically inactive disease in a prospective cohort of patients with juvenile idiopathic arthritis? the importance of definition. Ann Rheum Dis 2017:76:1381-8.
3 Dewoolkar M, Cimaz R, Chickermane PR, et al. Course, outcome and complications in children with systemic onset juvenile idiopathic arthritis. Indian J Pediatr 2017;84:294-8.

4 Ravelli A, Martini A. Juvenile idiopathic arthritis. The Lancet 2007;369:767-78.

5 Nordstrom BL, Mines D, Gu Y, et al. Risk of malignancy in children with juvenile idiopathic arthritis not treated with biologic agents. Arthritis Care Res 2012;64:1357-64.

6 Mannion ML, Beukelman T. What is the background incidence of malignancy in children with rheumatic disease? Curr Rheumatol Rep 2013;15:310.

7 Simard JF, Neovius M, Hagelberg S, et al. Juvenile idiopathic arthritis and risk of cancer: a nationwide cohort study. Arthritis Rheum 2010;62:3776-82.

8 Diak P, Siegel J, La Grenade L, et al. Tumor necrosis factor alpha blockers and malignancy in children: forty-eight cases reported to the food and drug administration. Arthritis Rheum 2010;62:2517-24.

9 Beukelman T, Xie F, Chen L, et al. Risk of malignancy associated with paediatric use of tumour necrosis factor inhibitors. Ann Rheum Dis 2018;77:1012-6.

10 Klotsche J, Niewerth M, Haas J-P, et al. Long-Term safety of etanercept and adalimumab compared to methotrexate in patients with juvenile idiopathic arthritis (JIA). Ann Rheum Dis 2016;75:855-61.

11 Zahedi Niaki O, Clarke AE, Ramsey-Goldman R, et al. Malignancy incidence in 5294 patients with juvenile arthritis. RMD Open 2016;2:e000212.

12 Kok VC, Horng J-T, Huang J-L, et al. Population-Based cohort study on the risk of malignancy in East Asian children with juvenile idiopathic arthritis. BMC Cancer 2014;14:634.

13 Bernatsky S, Rosenberg AM, Oen KG, et al. Malignancies in juvenile idiopathic arthritis: a preliminary report. J Rheumatol 2011;38:760-3. 